\title{
Identification of viridans streptococci by pyrolysis-gas chromatography
}

\author{
G. L.FRENCH*, H. TALSANIA and I.PHILLIPS
}

\begin{abstract}
Department of Microbiology, United Medical and Dental Schools of Guy's and St Thomas's, St Thomas's Campus, London SE1 TEH
\end{abstract}

\begin{abstract}
Summary. An isothermal method of pyrolysis-gas chromatography (Py-GC) was used for the identification of viridans streptococci. Pyrograms from 104 reference strains were subjected to a discriminant analysis to produce classification coefficients for the identification of 74 test organisms. Five groups representing recognised species were discriminated but Streptococcus milleri strains could not be distinguished from $S$. sanguis. If $S$. milleri and $S$. sanguis are regarded as a single pyrogroup, only three strains out of 74 were incorrectly identified by Py-GC. A multidimensional scaling analysis of the Py-GC data produced a similar species grouping, but this statistical method was less satisfactory for pyrogram data than discriminant analysis. While PyGC was moderately successful for the identification of viridans streptococci, this study indicated that the technique has limited use in diagnostic medical microbiology because it is time-consuming and lacks flexibility.
\end{abstract}

\section{Introduction}

Bacteria can be characterised by gas-chromatographic analysis, either by detection of specific chemical components or by "fingerprint" patterns of chromatographic peaks; the latter may be used for speciation and identification even when the chemical nature of the peaks is unknown (Drucker, 1976, 1981). Conventional methods for the production of volatile chemical derivatives suitable for gas-chromatography are complex and time-consuming. An alternative technique is pyrolysis-gas chromatography (Py-GC), in which bacterial cultures are volatilised by heat-shock in a pyrolyser (Gutteridge and Norris, 1979). The resulting pyrolysis products are swept directly on to a gaschromatographic column for analysis, producing characteristic chromatographic patterns called pyrograms. The method has been criticised for its poor reproducibility (Seviour et al., 1974; Wickman, 1977; Brosseau and Carmichael, 1978; French et al., 1980), but we have developed a new technique of Py-GC employing isothermal oven temperatures and solid stationary phases that is both practical and reproducible (French et al., 1981).

There have been several previous studies of PyGC of viridans streptococci, but these have been

Received 4 June 1988; revised version accepted 29 Sept. 1988.

*Present address for correspondence: Professor G. L. French, Department of Microbiology, The Chinese University of Hong Kong, Shatin, N. T., Hong Kong. limited to small numbers of strains (Huis In't Veld et al., 1973; Drucker et al., 1975; Meuzelaar et al., 1975; Stack et al., 1977, 1978, 1982). In this paper we report the application of isothermal Py-GC to the identification of a larger collection of viridans streptococci previously speciated by physiological methods (French et al., 1989).

\section{Materials and methods}

\section{Organisms}

One hundred and seventy eight strains of viridans streptococci were used. They had been previously classified by physiological reactions into six speciesStreptococcus mutans, $S$. bovis, $S$. sanguis, $S$. mitior, $S$. salivarius and $S$. milleri (French et al., 1989). The organisms were divided into 104 reference strains for the construction of discriminant functions and 74 test strains for use as "unknowns" in the testing of these functions. The test group contained randomly chosen typical organisms, aesculin-positive $S$. mitior, aesculin-negative $S$. sanguis, all the $S$. bovis II strains and organisms that could not be classified intuitively (French et al., 1989). Each organism was cultured and pyrolysed in duplicate.

\section{Pyrolysis-GC}

Sample preparation. Pure cultures of organisms were grown overnight at $37^{\circ} \mathrm{C}$ in $\mathrm{CO}_{2} 10 \%$ in air on bacterial filters (type HA; Millipore (UK) Ltd, London). These were placed on blood agar (for analysis on the Chromo- 
sorb 103 column) and sucrose blood agar (for TenaxGC).

Normalisation and control organism. The control organism, $S$. mutans NCTC 10449, was pyrolysed several times and approximate percentage values for the different pyrogram peaks were established. These control values (table I) were then used as a set of "expected amounts" to adjust (or normalise) the peak values for day-to-day instrumental or biological variations; this procedure was performed automatically by the integrator (French $e$ t al., 1981). Mean normalised area values percent for each peak were determined for each organism pyrolysed in duplicate with each stationary phase.

Gas chromatography. The method was similar to that described previously (French et al., 1981). A Pye 204 gaschromatograph (Pye Unicam, Cambridge), was fitted with dual flame-ionisation detectors. Two low resolution coiled glass columns $(1.5 \mathrm{~m} \times 4 \mathrm{~mm}$ i.d. $)$ were used; one was packed with the polymer solid stationary phase Chromosorb 103 and the other with Tenax-GC (PhaseSeparations Ltd, Queensferry, Cllwyd). The two columns were mounted in the same oven and isothermal analyses were conducted at a constant $100^{\circ} \mathrm{C}$. The inlet (injector) heater was switched off, and the detector temperature was set at $250^{\circ} \mathrm{C}$. Oxygen-free nitrogen with a flow rate of $40 \mathrm{ml} / \mathrm{min}$ for Chromosorb 103 and $15 \mathrm{ml} / \mathrm{min}$ for Tenax-GC was used as the carrier gas. Organisms were pyrolysed first on one column and, after completion of data collection, on the other. Pyrograms were recorded with a Hewlett-Packard 3385A recording integrator.

Pyrolysis. Each column was fitted with a Pye 796014 curie-point pyrolyser with the coil situated within the oven enclosing the upper end of the chromotography column. Iron pyrolysis wires (Pye Unicam) were used with a pyrolysis temperature of $700^{\circ} \mathrm{C}$. The tips of the wires were positioned within the column in the centre of the pyrolysis unit, above the glass wool plug of the column packing and $7.5 \mathrm{~cm}$ below the septum cap. The wires were sheathed by quartz capillary tubes (Pye Unicam) inserted into the column and resting on the packing. High-boiling-point pyrolysates condensed on these tubes which were removed for cleaning after each pyrolysis. Wires were cleaned by flaming to red heat in a bunsen burner before each new specimen was processed, and wires and septa were changed daily. Fresh cultures of bacterial cells were transferred with a plastic sterile loop (Nunc, Roskilde, Denmark) to the terminal $3 \mathrm{~mm}$ of cleaned wires. Excess material was removed with the shaft of the loop, resulting in a specimen weight of less than $100 \mu \mathrm{g}$. Pyrolysis time was set at $8 \mathrm{~s}$.

Data analysis. Statistical analyses were performed at the London University Computing Centre. Discriminant analysis utilised the subprogram Discriminant from the Statistical Package for Social Sciences (SPSS) (Nie et al., 1975), and a specially written program for the production of graphical output (Healy, 1973). Predetermined species

Table I. Mean retention times (RT) and mean normalised area percentages of pyrogram peaks from reference organisms

\begin{tabular}{|c|c|c|c|c|c|c|c|c|}
\hline \multirow[b]{2}{*}{$\begin{array}{c}\text { Peak } \\
\text { no. }\end{array}$} & \multirow[b]{2}{*}{$\underset{(\mathrm{min})}{\mathrm{RT}}$} & \multicolumn{7}{|c|}{ Normalised area percentages of pyrogram peaks for } \\
\hline & & $\begin{array}{l}\text { control } \\
\text { strain* }\end{array}$ & $\begin{array}{c}S . \\
\text { mutans }\end{array}$ & $\begin{array}{c}S . \\
\text { salivarius }\end{array}$ & $\underset{\text { milleri }}{S .}$ & $\begin{array}{c}\text { S. } \\
\text { sanguis }\end{array}$ & $\begin{array}{c}S . \\
\text { mitior }\end{array}$ & $\begin{array}{c}S . \\
\text { bovis }\end{array}$ \\
\hline \multicolumn{9}{|c|}{ Pyrolysis with Chromosorb 103} \\
\hline 1 & 0.57 & $6 \cdot 0$ & $6 \cdot 8$ & $11 \cdot 9$ & $10 \cdot 6$ & $12 \cdot 1$ & $10 \cdot 2$ & $11 \cdot 8$ \\
\hline 2 & 0.86 & $9 \cdot 0$ & $11 \cdot 4$ & $17 \cdot 6$ & $16 \cdot 9$ & $18 \cdot 4$ & $15 \cdot 1$ & $15 \cdot 2$ \\
\hline 3 & 1.68 & $9 \cdot 0$ & $12 \cdot 0$ & $20 \cdot 7$ & $19 \cdot 4$ & $20 \cdot 9$ & $17 \cdot 5$ & $16 \cdot 1$ \\
\hline 4 & $2 \cdot 74$ & $5 \cdot 0$ & $4 \cdot 4$ & $1 \cdot 8$ & 1.6 & $1 \cdot 7$ & 7.9 & 1.0 \\
\hline $5 a$ & $4 \cdot 20$ & $4 \cdot 5$ & $6 \cdot 2$ & $10 \cdot 4$ & $9 \cdot 8$ & $10 \cdot 3$ & $9 \cdot 0$ & $8 \cdot 5$ \\
\hline $5 b$ & $4 \cdot 81$ & 0.5 & & & & & & \\
\hline 6 & 5.95 & $21 \cdot 0$ & $22 \cdot 1$ & $29 \cdot 8$ & $35 \cdot 5$ & $30 \cdot 9$ & $24 \cdot 5$ & $44 \cdot 7$ \\
\hline 7 & $8 \cdot 17$ & $45 \cdot 0$ & $37 \cdot 2$ & $7 \cdot 8$ & $6 \cdot 1$ & $5 \cdot 7$ & $15 \cdot 8$ & $2 \cdot 6$ \\
\hline \multicolumn{9}{|c|}{ Pyrolysis with Tenax-GC } \\
\hline 1 & 1.08 & $7 \cdot 0$ & $6 \cdot 4$ & $7 \cdot 1$ & $5 \cdot 6$ & 4.9 & $5 \cdot 8$ & $7 \cdot 4$ \\
\hline 2 & $1 \cdot 34$ & $6 \cdot 0$ & $5 \cdot 5$ & $5 \cdot 7$ & $5 \cdot 2$ & $5 \cdot 2$ & $5 \cdot 6$ & $5 \cdot 4$ \\
\hline 3 & $2 \cdot 14$ & $4 \cdot 5$ & $4 \cdot 2$ & $4 \cdot 1$ & $4 \cdot 5$ & $4 \cdot 3$ & $4 \cdot 9$ & $4 \cdot 4$ \\
\hline $4 a$ & $2 \cdot 71$ & $3 \cdot 0$ & $3 \cdot 3$ & $2 \cdot 1$ & $4 \cdot 2$ & $3 \cdot 7$ & $5 \cdot 0$ & $3 \cdot 1$ \\
\hline $4 b$ & $3 \cdot 25$ & $1 \cdot 0$ & & & & & & \\
\hline 5 & $4 \cdot 71$ & $15 \cdot 0$ & $12 \cdot 3$ & $11 \cdot 3$ & $14 \cdot 5$ & $11 \cdot 0$ & $12 \cdot 0$ & $16 \cdot 5$ \\
\hline 6 & 5.50 & $2 \cdot 0$ & $2 \cdot 0$ & 1.6 & 1.9 & 1.9 & $2 \cdot 3$ & 1.9 \\
\hline 7 & $12 \cdot 79$ & $6 \cdot 0$ & 5.8 & $4 \cdot 8$ & $7 \cdot 3$ & 6.9 & $6 \cdot 7$ & $4 \cdot 7$ \\
\hline 8 & 14.45 & $10 \cdot 5$ & $11 \cdot 4$ & 18.8 & 9.0 & 9.7 & 9.0 & $10 \cdot 1$ \\
\hline 9 & 16.79 & $40 \cdot 0$ & $41 \cdot 6$ & $37 \cdot 5$ & $42 \cdot 5$ & $44 \cdot 4$ & $41 \cdot 7$ & 38.5 \\
\hline 10 & $26 \cdot 81$ & $5 \cdot 0$ & 7.6 & $7 \cdot 2$ & $5 \cdot 4$ & 7.9 & $7 \cdot 1$ & 8.0 \\
\hline
\end{tabular}

*The constant peak area percentage value for the control organism $S$. mutans NCTC 10449 used in the normalisation procedure. 
groups were specified for the 104 reference strains, and a discriminant analysis was performed on the combined 17-peak pyrogram data from both chromatography columns. The 74 test organisms were then allocated to one of the six species groups by the discriminant classification coefficients.

The pyrogram data were also analysed by multidimensional scaling (Kruskal, 1964a,b; Guttman, 1969) with the MINISSA (Michigan-Israel-Nijmegen-IntegratedSmall-Space-Analysis) program (Lingoes and Roskam, 1973; Report, 1977). This ordination technique attempts to find a configuration of points in low dimensional space (ideally in two or three dimensions) that preserves their relationship in multidimensional space. Classical multidimensional scaling aims to preserve the distance relationships between individuals whereas non-metric multidimensional scaling preserves the rank order of their similarities. Since "distance" has no real meaning for pyrolysis data, the non-metric method was used. The program optimises the goodness-of-fit of the solution by minimising a function defined by Kruskal which he calls "Stress" and which is called "DHAT" in MINISSA. The remaining DHAT or stress value is a measure of the validity of the final solution. The MINISSA program can accommodate data for only 70 organisms; these were chosen from the reference strains to give an approximately equal number of physiologically typical representatives from each of the six species.
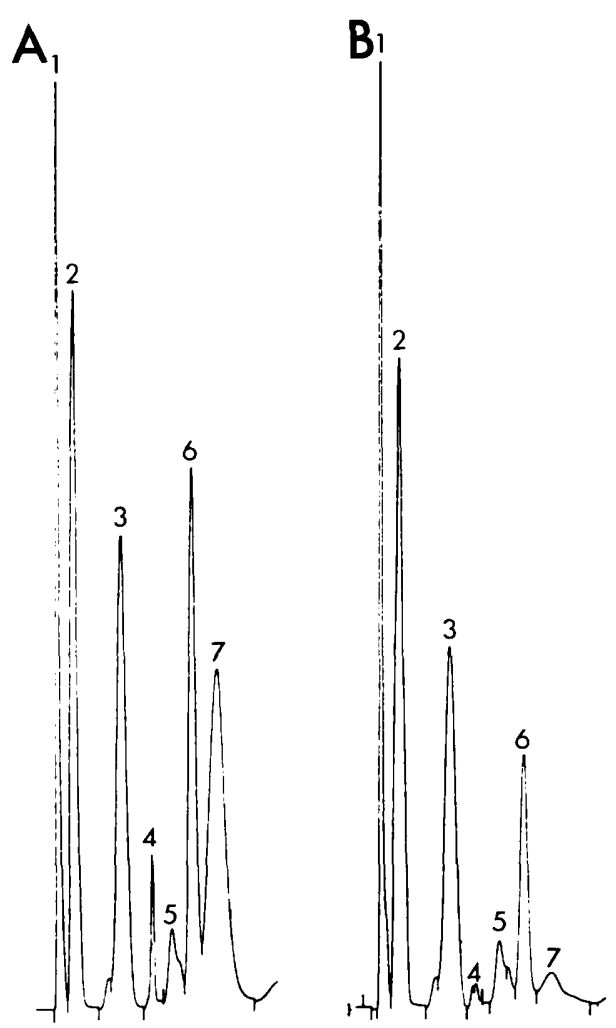

Fig. 1. Typical pyrograms from organisms grown on blood agar and analysed with Chromosorb 103. (A) S. mutans, (B) S. salivarius, (C) $S$. mitior. The numbers show the peaks used in discriminant analysis.

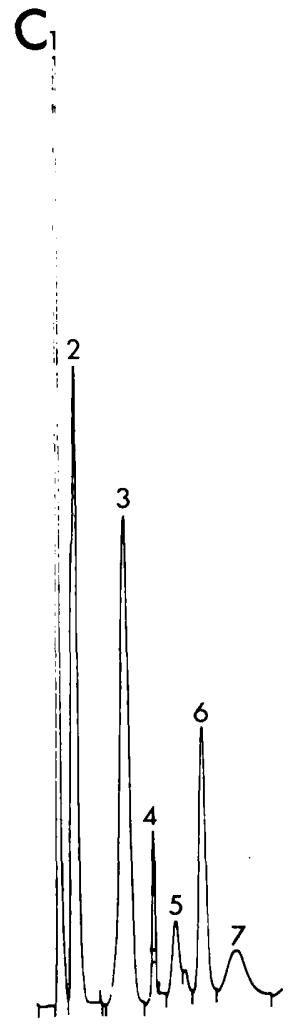

\section{Results}

All strains of viridans streptococci produced the same pyrogram peaks, but these differed quantitatively (figs. 1 and 2). Seven groups of peaks were produced with Chromosorb 103 and 10 with TenaxGC. These were usually baseline-resolved, but peak 5 of the Chromosorb pyrogram and peak 4 of the Tenax-GC pyrogram were often resolved into two. These peak pairs were summed for analysis, so that 17 pyrogram peaks were utilised.

Normalised peak values were reproducible, and certain species could be distinguished visually, e.g., $S$. mutans had a large Chromosorb 103 peak 7 , with a percentage area $c .40 \%$, compared with values as low as $2.6 \%$ for $S$. bovis (table I). An analysis of variance using Duncan's procedure showed that there were significant differences at the 0.05 level among the six groups for all peaks except peaks 2 and 10 of the Tenax-GC pyrograms. Further analysis required the use of multivariate methods. Seventeen-peak data for the 104 reference strains were used in a discriminant analysis to distinguish the six species $S$. mutans, $S$. salivarius, $S$. milleri, $S$. sanguis, $S$. mitior and $S$. bovis.

With six species groups there are five discrimi- 


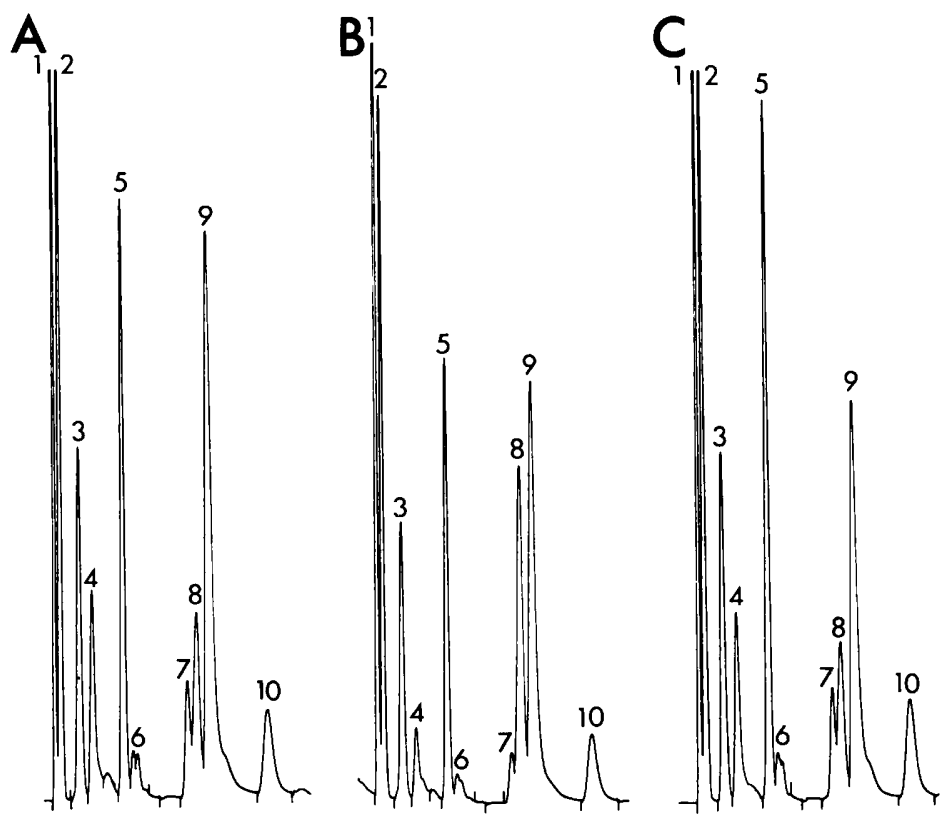

Fig. 2. Typical pyrograms from organisms grown on sucrose blood agar and analysed with Tenax-GC. (A) S. mutans, (B) S. salivarius, (C) $S$. bovis I. The numbers show the peaks used in discriminant analysis.

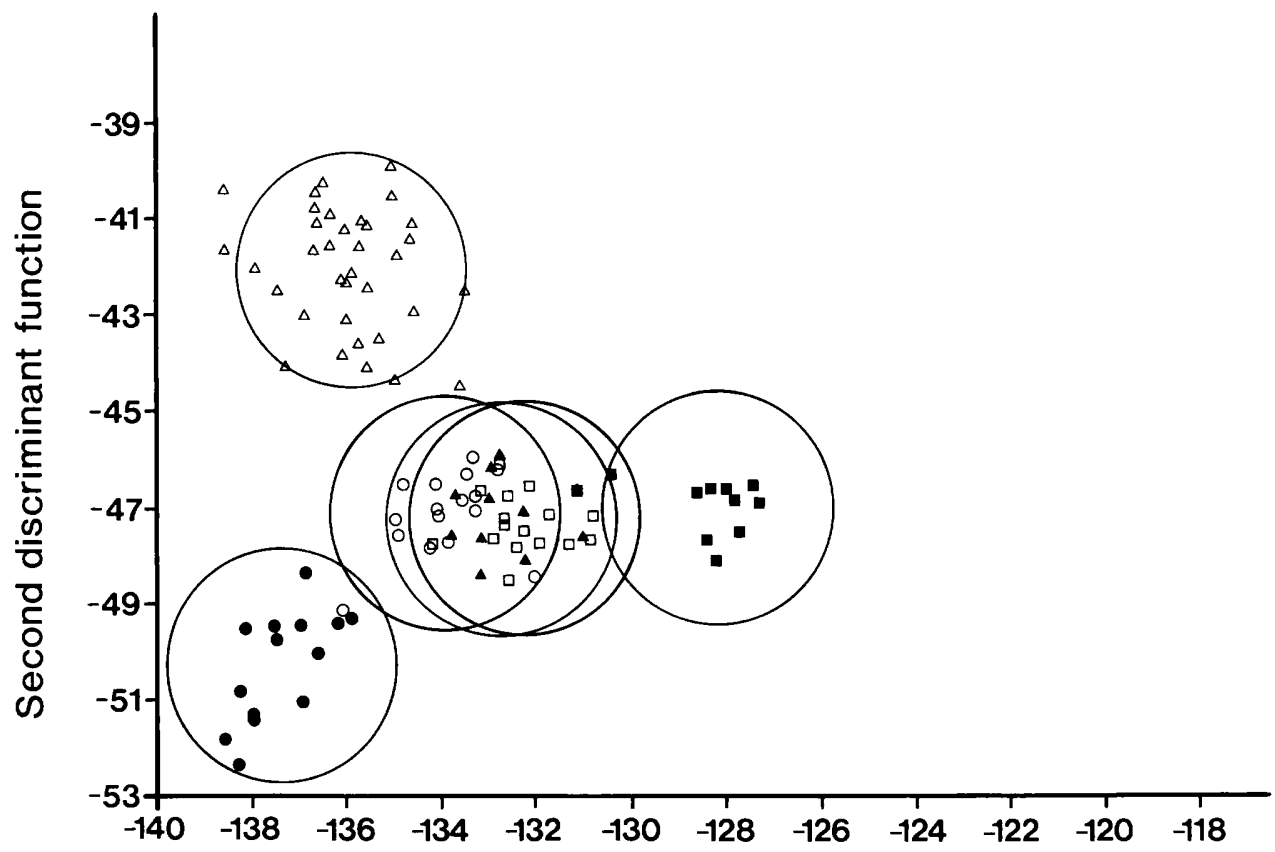

First discriminant function

Fig. 3. Discriminant analysis of pyrogram data from 104 reference strains of viridans streptococci showing the plots of the first two discriminant functions. The circles are the $95 \%$ confidence ranges of the species groups. $\triangle=S$. mutans; $\Delta=S$. salivarius; $\bigcirc=S$. sanguis; $=$ S. mitior; $\square=S$. milleri; $\square=S$. bovis $\mathrm{I}$. 


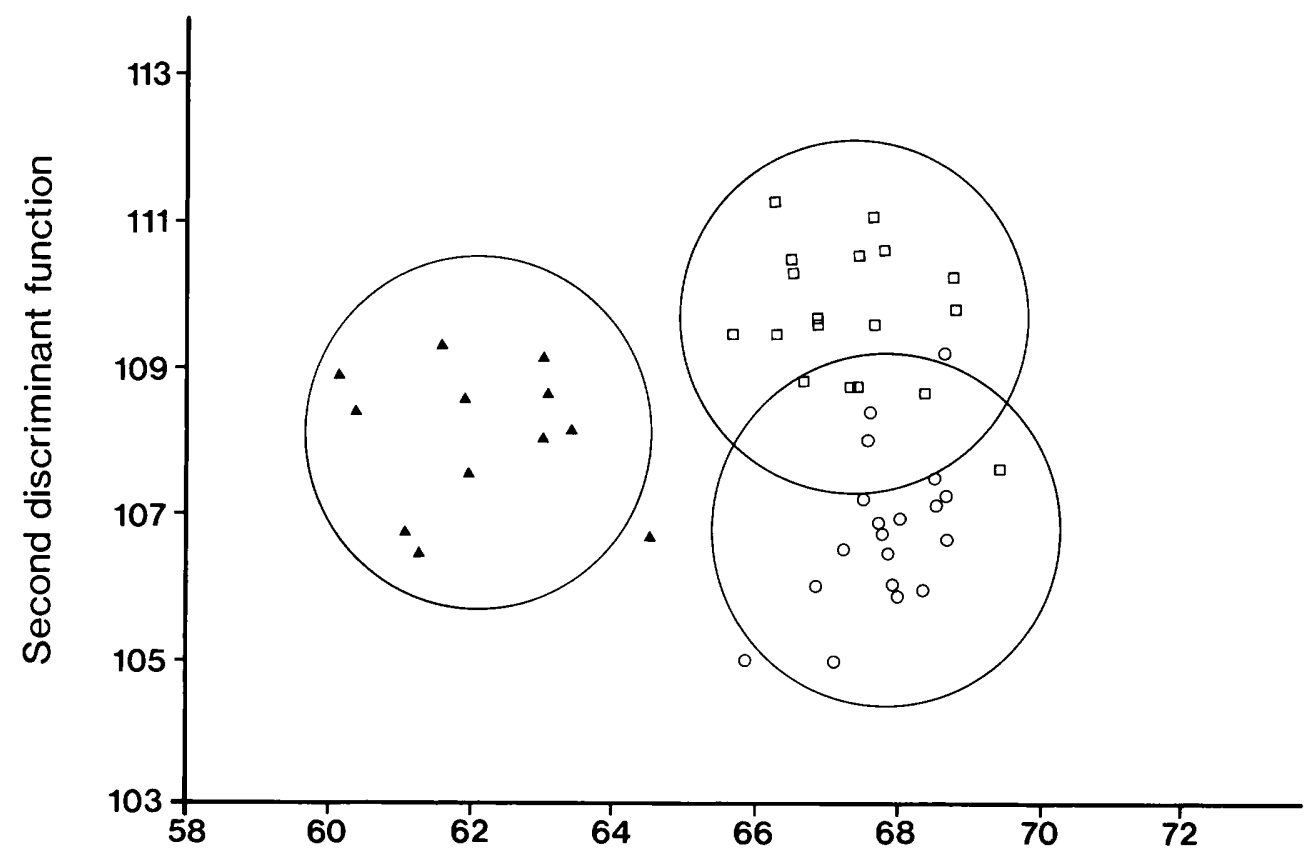

First discriminant function

Fig. 4. Discriminant analysis of pyrogram data from reference strains of $S$. sanguis, $S$. milleri and $S$. salivarius showing the plots of the first two discriminant functions. The circles represent $95 \%$ confidence ranges of the species groups. $\Delta=S$. salivarius; $O=S$. sanguis; $\square=S$. milleri.

nant functions. The circles in fig. 3 are the $95 \%$ tolerance ranges of the species groups for the first two discriminant functions calculated from data from the reference set of organisms. The first function displays $49.3 \%$ of the total variation, the second $28.8 \%$, the third $12.3 \%$, the fourth $8.3 \%$ and the fifth $1.3 \%$. Thus $78.1 \%$ of the total variation is displayed in this two-dimensional view. Table II gives the generalised (Mahalanobis $\mathrm{D}^{2}$ ) distances in multidimensional space among the six group centroids. Complete separation between groups is achieved by a $\mathrm{D}^{2}$ of $6 \cdot 65$.
S. mutans, S. bovis and S. mitior are well separated in two dimensions, but there is overlap between $S$. salivarius, $S$. sanguis and $S$. milleri (fig. 3). Table II shows that in multidimensional space $S$. salivarius is separated from both $S$. sanguis and $S$. milleri by 5.3 units, but the latter two groups cannot be distinguished. A separate discriminant analysis of these three species confirmed the discrimination of the $S$. salivarius strains (fig. 4).

The discriminant analysis could, therefore, distinguish five "pyrogroups" consisting of four species-S. mutans, S. bovis, S. mitior and S. salivarius-

Table II. Generalised (Mahalanobis D2) distances between group centroids for the pyrogram data from 104 reference strains of viridans streptococci

Generalised distance from*

\begin{tabular}{|c|c|c|c|c|c|}
\hline Species group & S. mutans & S. mitior & S. salivarius & S. bovis & S. sanguis \\
\hline$S$. mitior & $8 \cdot 4$ & & & & \\
\hline S. salivarius & $7 \cdot 7$ & $7 \cdot 6$ & & & \\
\hline S. bovis & $9 \cdot 2$ & $9 \cdot 7$ & $7 \cdot 2$ & & \\
\hline S. sanguis & $6 \cdot 3$ & 5.9 & $5 \cdot 3$ & 6.9 & \\
\hline S. milleri & 6.9 & 6.7 & $5 \cdot 3$ & $5 \cdot 2$ & 2.6 \\
\hline
\end{tabular}

Minimum distance for complete separation with five canonical variates is $6 \cdot 65$. 
and a single group for $S$. milleri and $S$. sanguis. This analysis of the reference strains produced a series of classification coefficients that could be used to identify the 74 test strains. The coefficients were applied to the peak values of pyrograms from the test strains to produce scores for each discriminant function. The scores for the first two functions were used to plot the positions of the test strains relative to the reference groups in the first two dimensions. Plots of pyrograms from the test strains fell close to those of the reference strains in the plane of the first two discriminant functions, indicating that the pyrograms were reproducible and that spurious results were uncommon (fig. 5). For each test strain the analysis also calculates the relative likelihood of group membership and the $\mathrm{D}^{2}$ distance from each group centroid in multidimensional space. By this means the test strains could be identified.

With this method, 55 of the 74 test strains were correctly identified, but 19 were given different identities to those obtained previously by cluster analysis or intuitive classification (French et al., 1989) (table III). Because $S$. sanguis and $S$. milleri could not be distinguished in the discriminant analysis of reference strains several of the test strains of these species were inevitably identified wrongly; nine of the 19 mis-classifications were due to confusion between these two species (table III).

Several other wrongly identified organisms were atypical or of doubtful identity. The atypical $S$. sanguis reference strains NCTC 7868 and $\mathrm{HF} /$ F90A (ATCC 12369) which clustered with $S$. milleri in a numerical taxonomy, were both identified as $S$. sanguis by Py-GC. The atypical $S$. mitior-like strain STH135(J), arginine-negative but containing large amounts of rhamnose (Price et al., 1986), was classified intuitively as $S$. mitior on the basis of physiological reactions but grouped with $S$. sanguis on a cluster analysis; it was identified as $S$. sanguis by Py-GC. Strain STH102 resembles $S$. sanguis but is $\mathrm{H}_{2} \mathrm{O}_{2}$-negative, and clustered with $S$. mitior; it was identified as $S$. sanguis by Py-GC. Two other $\mathrm{H}_{2} \mathrm{O}_{2}$-negative strains, STH11 and STH20, clustered with $S$. milleri but could not be identified intuitively. These were allocated to $S$. mitior and $S$. sanguis respectively by Py-GC, identifications that correspond with the results of arginine hydrolysis. The atypical $S$. salivarius strain LINH 33142 (STH130) (raffinose-negative, $\beta$-galactosidase-negative, urease-negative) that had been grouped with

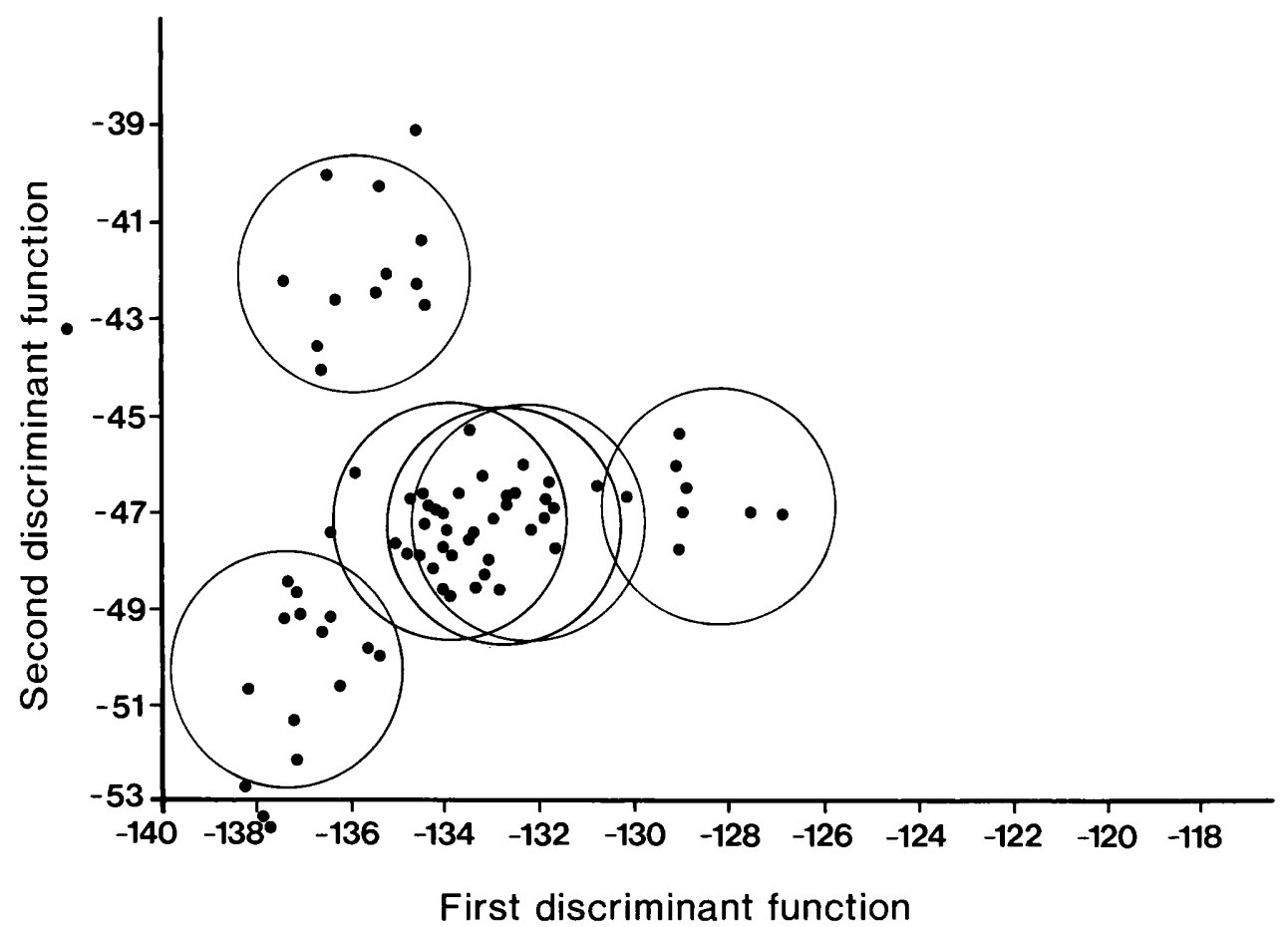

Fig. 5. Use of discriminant analysis of pyrogram data for the classification of 74 test strains. The circles are the $95 \%$ confidence ranges of the species groups in the first two dimensions previously calculated from pyrograms of the reference strains (see fig. 3 ). The symbols are the plots of the test strains in the first two dimensions calculated from the previous discriminant analysis. 
Table III. Organisms with Py-GC identities different from those given by intuitive classification or cluster analysis (French et al., 1989)

\begin{tabular}{|c|c|c|c|c|}
\hline $\begin{array}{l}\text { STH } \\
\text { code }\end{array}$ & $\begin{array}{l}\text { Original } \\
\text { code }\end{array}$ & $\begin{array}{c}\text { Intuitive } \\
\text { identification }\end{array}$ & $\begin{array}{c}\text { Cluster } \\
\text { membership }\end{array}$ & $\begin{array}{c}\text { Py-GC } \\
\text { identification }\end{array}$ \\
\hline \multicolumn{5}{|c|}{$\begin{array}{l}\text { Organisms wrongly identified because of the confusion } \\
\text { between } S \text {. milleri and } S . \text { sanguis }\end{array}$} \\
\hline 010 & SVIR 891 & S. milleri & VI $S$. milleri & S. sanguis \\
\hline 040 & R79/3327 & S. milleri & VI S. milleri & S. sanguis \\
\hline 082 & SHAW 898 & S. milleri & VI $S$. milleri & S. sanguis \\
\hline 084 & MCELROY 663 & S. milleri & VI $S$. milleri & S. sanguis \\
\hline 055 & BC: 1736 & S. sanguis & IV $S$. sanguis & S. milleri \\
\hline 097 & LH867/80BC & S. sanguis & IV $S$. sanguis & S. milleri \\
\hline 164 & SINGH & S. sanguis & IV $S$. sanguis & S. milleri \\
\hline 166 & KENDALL & S. sanguis & IV $S$. sanguis & S. milleri \\
\hline 015 & STH23 & S. sanguis & IV $S$. sanguis & S. milleri \\
\hline \multicolumn{5}{|c|}{ Physiologically atypical organisms } \\
\hline 179 & NCTC 7868 & S. sanguis & VI $S$. milleri & S. sanguis \\
\hline 113 & $\mathrm{HF} / \mathrm{F} 90 \mathrm{~A}$ & $S$. sanguis & VI $S$. milleri & S. sanguis \\
\hline 135 & $J$ & S. mitior & IV $S$. sanguis & S. sanguis \\
\hline 102 & LH045/80BC & S. sanguis & III $S$. mitior & S. sanguis \\
\hline 011 & ANDERSON 95 & $?$ & VI $S$. milleri & S. mitior \\
\hline 020 & 850356 & $?$ & VI $S$. milleri & S. sanguis \\
\hline 130 & LINH 33142 & S. salivarius & VI $S$. milleri & S. milleri \\
\hline \multicolumn{5}{|c|}{ Physiologically typical organisms } \\
\hline 138 & $\mathbf{M}$ & S. bovis & II $S$. bovis & S. milleri \\
\hline 050 & STREP 290 & S. salivarius & V S. salivarius & S. milleri \\
\hline 094 & LH537/80BC & S. mitior & III S. mitior & S. sanguis \\
\hline
\end{tabular}

S. milleri in a cluster analysis of physiological reactions (French et al., 1989) was also identified as $S$. milleri by Py-GC.

If the confusion between $S$. milleri and $S$. sanguis is ignored, and the physiologically atypical strains excluded, only three strains out of 74 were wrongly identified by discriminant analysis of Py-GC data (table III). These were $S$. bovis I strain STH138, identified as $S$. milleri, $S$. salivarius strain STH50, identified as $S$. milleri, and the aesculin-positive $S$. mitior strain STH94, identified as $S$. sanguis (table III).

Py-GC results from 70 organisms were also analysed by multidimensional scaling. Both twodimensional and three-dimensional solutions were computed. The three-dimensional solution had a "stress" (DHAT) of 0.06, and the two-dimensional solution one of $0 \cdot 11$. The first value is considered "fair", and the second "moderate" (Report, 1977). The plot of the two dimensional solutions is shown in fig. 6. In this figure, points representing members of the same species are joined by lines. Overlap occurs amongst the species, especially $S$. salivarius, $S$. milleri and $S$. sanguis. The two-dimensional plot is similar to the discriminant analysis in that the three other species are well-separated in this view. The importance of this result is that this technique - which uses no preconceived grouping of the data - produces a two-dimensional display remarkably similar to that given by the discriminant analysis which used a predetermined group structure.

\section{Discussion}

These results show that our isothermal method of Py-GC is reproducible and practical for bacterial identification. Some of the viridans species produced characteristic pyrogram patterns that could be identified visually, but the data were more successfully interpreted by discriminant analysis (MacFie et al., 1978, French et al., 1981). Discriminant analysis requires the establishment of predetermined groups, and in this study six species of viridans streptococci were defined by a previous physiological classification.

The analysis was first applied to 104 reference strains of known identity. This produced a reasonably satisfactory discrimination of the species groups. The analysis clearly discriminated between $S$. mitior and $S$. sanguis, and there was good separation of $S$. mutans and $S$. bovis; however, $S$. milleri and $S$. sanguis could not be distinguished. These two organisms do have some similarities of physiological characteristics, but are relatively easy to identify by conventional methods. 


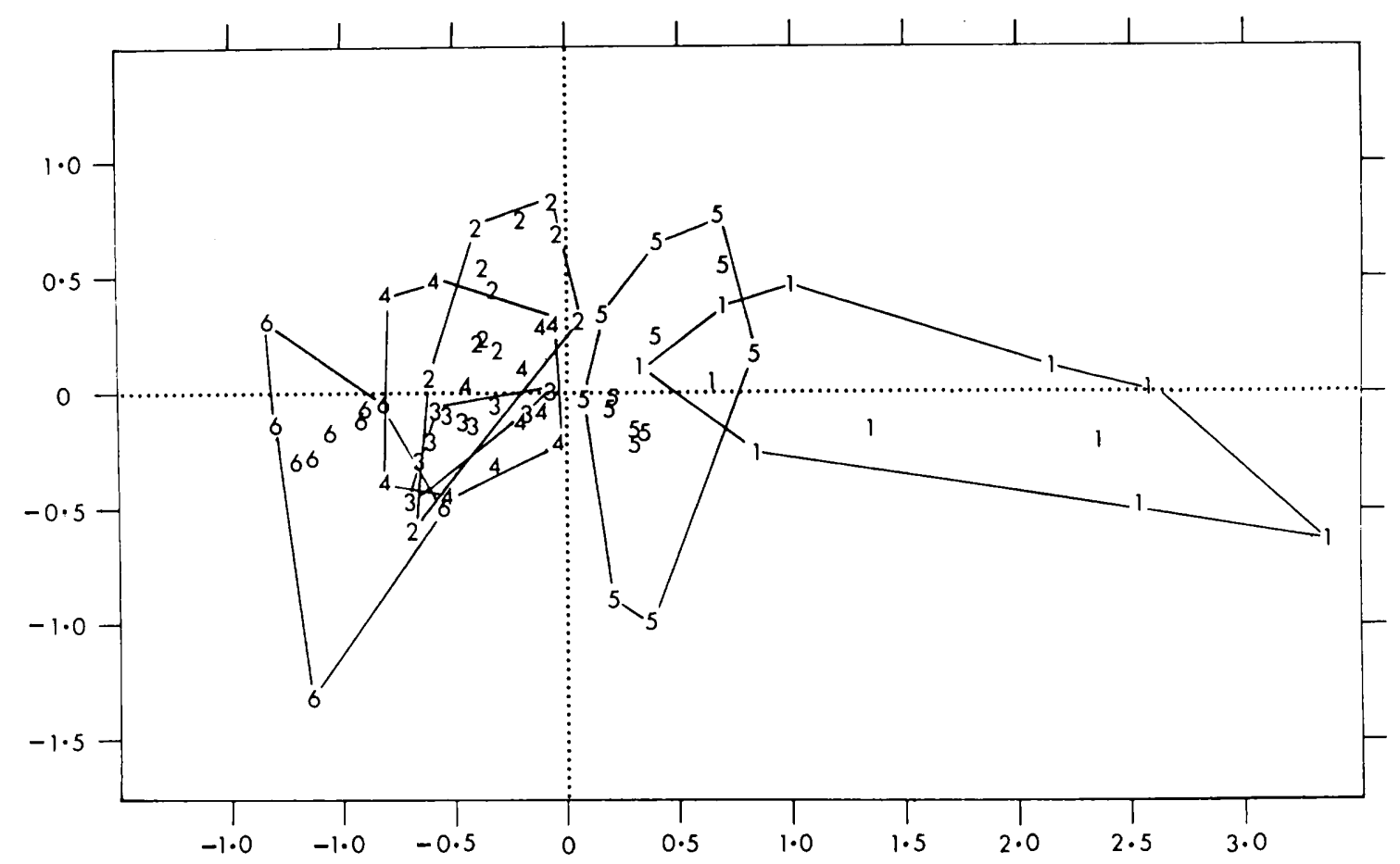

Fig. 6. Analysis of pyrogram data by multidimensional scaling. Pyrogram data from 70 reference strains were subjected to multidimensional scaling analysis by the MINISSA program. The graph shows the plot of the two-dimensional solution with a DHAT (Stress) of $0 \cdot 11.1=S$. mutans; $2=S$. salivarius; $3=S$. milleri; $4=S$. sanguis $;=S$. mitior $; 6=S$. bovis.

Discrimination was tested by classifying pyrograms from 74 test strains according to the classification coefficients calculated from the analysis of the reference strains. The plots of these data in two dimensions showed that the pyrograms of different species were reproducible and tended to fall close to the centroids of the appropriate reference species. The test strains were identified by allocation to the species group closest to them in multidimensional space. If $S$. milleri and $S$. sanguis are regarded as a single pyrogroup, most strains were correctly identified, including several viridans strains that were difficult to speciate on physiological grounds. However, three strains with typical physiological reactions were wrongly classified by this method.

Discriminant analysis is satisfactory for bacterial identification, but less so for the construction of a taxonomy since it requires the species groups to be known. Therefore, a multidimensional scaling analysis was performed on Py-GC data from 70 organisms (the maximum that could be accommodated by our program). This method has been used successfully for bacterial Py-GC by Eshuis et al., (1977). In the present study there was considerable overlap between the species when plotted in twodimensional space. However, the pattern of the species plots was very similar to that produced by the discriminant analysis, providing further evidence that the intuitive grouping was valid.

This study has demonstrated that Py-GC can be used to identify viridans streptococci with reasonable success, but a number of problems remain. Firstly, S. milleri and $S$. sanguis cannot be distinguished. Secondly, because of the sequential nature of gas chromatographic analysis, analysis of large numbers of strains is very time-consuming. Thirdly, a simple set of physiological tests is more convenient and successful for viridans identification, and the use of Py-GC does not offer any obvious advantages.

There is a further inherent problem of Py-GC: whether two species can be discriminated by PyGC is largely a matter of chance, and the results cannot easily be improved by apparently logical experimentation. With other methods of chemotaxonomy, different chemical groups can be analysed by optimal methods, but in Py-GC there is no control over the composition of the pyrolysate which is analysed with a non-specific stationary phase. In a previous study we found that analysis 
by Chromosorb 103 alone was inadequate for viridans identification (French and Phillips, 1982). We then postulated that the stationary phase TenaxGC, which we found to be suitable for the analysis of sugars and polysaccharides, would be a good stationary phase for the analysis of sucrose-grown viridans streptococci (French and Phillips, 1982). In practice, data from both stationary phases had to be combined for satisfactory discrimination, and the Tenax-GC column did not distinguish polysaccharide-producing strains as had been anticipated. The chemical composition of the pyrogram peaks in this study remains unknown.

In conclusion, we have found Py-GC to be

\section{REFERENCES}

Brosseau J D, Carmichael J W 1978 Pyrolysis gas-liquid chromatography applied to a study of variation in Arthroderma tuberculatum. Mycopathologia 63: 67-69.

Drucker D B 1976 Gas-liquid chromatographic chemotaxonomy. In: Norris J R (ed) Methods in microbiology, vol 9. Academic Press, London, pp 52-125.

Drucker D B 1981 Microbiological applications of gas chromatography. Cambridge University Press, Cambridge.

Drucker D B, Holmes C, Stack M V, Donoghue H D, Tyler J E, Marshall M 1975 Comparison of two GLC techniques for identifying streptococci of several Lancefield groups. Journal of Applied Bacteriology 39: viii-ix (Abstract).

Eshuis W, Kistemaker P G, Meuzelaar H L C 1977 Some numerical aspects of reproducibility and specificity. In: Jones C E R, Cramers C A (eds) Analytical pyrolysis. Elsevier, Amsterdam, pp 151-166.

French G L, Gutteridge C S, Phillips I 1980 Pyrolysis gaschromatography of Pseudomonas and Acinetobacter species. Journal of Applied Bacteriology 49 : 505-516.

French G L, Phillips I, Chinn S 1981 Reproducible pyrolysisgas chromatography of micro-organisms with solid stationary phases and isothermal oven temperatures. Journal of General Microbiology 125 : 347-355.

French G L, Phillips I 1982 Discrimination and identification of oral streptococci by pyrolysis-gas chromatography. In: Holm SE, Christensen P (eds) Basic concepts of streptococci and streptococcal diseases. Reedbooks, Chertsey, Surrey, pp 62-64.

French G L, Talsania H, Charlton J, Phillips I 1989 A physiological classification of viridans streptococci by use of the API-20STREP system. Journal of Medical Microbiology 28 : $275-286$.

Gutteridge C S, Norris J R 1979 The application of pyrolysis techniques to the identification of micro-organisms. Journal of Applied Bacteriology 47: 5-43.

Guttman L 1969 A general nonmetric technique for finding the smallest coordinate space for a configuration of points. Psychometrika 33: 469-506.

Healy M J R 1973 Advanced technology in the hospital laboratory: handling and interpreting multiple results. Proceedings of the Royal Society B184: 369-374.

Huis In't Veld J H J, Meuzelaar H L C, Tom A 1973 Analysis of streptococcal cell wall fractions by curie-point pyrolysis gas-liquid chromatography. Applied Microbiology 26: 9297.

Kruskal J B $1964 a$ Multidimensional scaling by optimizing moderately successful for the identification of viridans streptococci, but less effective and convenient than simple physiological methods. The technique is time-consuming, limited in application, and, in our hands, incapable of further development or refinement. Py-GC for microbial analysis was first proposed over 20 years ago (Reiner, 1965), but despite improvements in pyrolysers, stationary phases and computerised analytical techniques, it has not evolved into a practical or useful microbiological method.

We are grateful to Susan Chinn, Department of Community Medicine, United Medical and Dental Schools, for performing the discriminant analysis.

goodness of fit to a non-metric hypothesis. Psychometrika 29: $1-27$.

Kruskal J B $1964 b$ Nonmetric multidimensional scaling: a numerical method. Psychometrika 29: 115-129.

Lingoes J C, Roskam E E 1973 A mathematical and empirical study of two multidimensional scaling algorithms. Psychometrika 38: Monograph 19.

MacFie H J H, Gutteridge C S, Norris J R 1978 Use of canonical variates analysis in differentiation of bacteria by pyrolysis gas-liquid chromatography. Journal of General Microbiology 104: 67-74.

Meuzelaar H L C, Kistemaker P G, Tom A 1975 Rapid and automated identification of microorganisms by Curie-point pyrolysis techniques. I. Differentiation of bacterial strains by fully automated Curie-point pyrolysis gas-liquid chromatography. In: Heden C G, Illeni $T$ (eds) New approaches to the identification of microorganisms. John Wiley and Sons, New York, pp 165-178.

Nie N H, Hull C H, Jenkins J G, Steinbrenner K, Bent D H 1975 Statistical package for the social sciences (SPSS). 2nd edn. McGraw-Hill, New York.

Price T, French G L, Talsania H, Phillips I 1986 Differentiation of Streptococcus sanguis and $S$. mitior by whole-cell rhamnose content and possession of arginine dihydrolase. Journal of Medical Microbiology 21 : 189-197.

Reiner E 1965 Identification of bacterial strains by pyrolysis gas-liquid chromatography. Nature 200: 1272-1274.

Report 1977 The MDS(X) series of multidimensional scaling programs. University of Edinburgh, Program Library Unit, Inter-University/Research Councils series; Report No. 32.

Seviour R J, Chilvers G A, Crow W D 1974 Characterization of eucalypt mycorrhizas by pyrolysis gas chromatography. New Phytology 73: 321-332.

Stack M V, Donoghue H D, Tyler J E, Marshall M 1977 Comparison of oral streptococci by pyrolysis gas liquid chromatography. In: Jones C E R, Cramers C A (eds) Analytic pyrolysis. Elsevier, Amsterdam, pp 57-68.

Stack M V, Donoghue H D, Tyler J E 1978 Discrimination between oral streptococci by pyrolysis gas-liquid chromatography. Applied and Environmental Microbiology 35: 45 50 .

Stack M V, Donoghue H D, Tyler J E 1982 Differentiation of Streptococcus mutans serotypes by discriminant analysis of pyrolysis-gas-liquid chromatography data. Journal of Analytical and Applied Pyrolysis 3: 221-227.

Wickman K 1977 Pyrolysis-gas-liquid chromatography of mycobacteria. Acta Pathologia et Microbiologica Scandinivica Suppl 259B : 49-53. 